\title{
Co-simulation Workflow for the Dynamic Modelling and Simulation of Large-scale District Energy Systems
}

\author{
Peter Nageler ${ }^{1}$, Gerald Schweiger ${ }^{2}$, Hermann Schranzhofer ${ }^{1}$, Richard Heimrath ${ }^{1}$, Thomas Mach ${ }^{1}$, \\ Lisa Marie Fochler ${ }^{1}$, Christoph Hochenauer ${ }^{1}$, Jürgen Fluch ${ }^{2}$, Ingo Leusbrock ${ }^{2}$, Christian Fink ${ }^{2}$ \\ ${ }^{1}$ Institute of Thermal Engineering, Graz University of Technology, Graz, Austria \\ ${ }^{2}$ AEE - Institute for Sustainable Technologies, Graz, Austria
}

\begin{abstract}
With the increasing complexity of urban energy systems, the requirements for modelling and simulation methods have increased. Co-simulation is a promising approach for carrying out system simulations, in which the respective sub systems are modelled using tailored tools. This paper presents a workflow for dynamic simulation of large-scale district energy systems introducing three main improvements compared to the state of the art: i) The data preparation was carried out using Vectorworks and QGIS; ii) A novel pipe-laying algorithm with grid dimensioning is introduced; iii) A co-simulation framework was applied to assess energy supply variations. The tools Dymola, IDA ICE and TRNSYS are thus coupled using cosimulation. The framework was applied on a virtual district: Different energy supply strategies were compared and the temperature increase due to global warming on the energy supply was investigated.
\end{abstract}

\section{Introduction}

Simulation-driven assessments and developments are regarded as key methods for addressing the growing complexity of future urban energy systems (Schweiger et al., 2018a). There are two possibilities for the modelling and simulation of complex systems that consist of several subsystems such as production units, buildings incl. Heating, ventilation and air conditioning (HVAC) systems, on-grid energy systems or storages: (i) the entire system is modelled and simulated in a single tool which is referred to as monolithic simulation; or (ii) established tools for the respective subsystems are coupled in a socalled co-simulation. Each simulation tool is seen as a black box, capable of producing outputs and consuming inputs, depending on the model it represents.

Recent work has discussed the advantages and disadvantages of both approaches (Schweiger et al., $2018 \mathrm{~b})$. The following is a summary of the factors that are relevant for the simulation of urban energy systems: (i) it is sometimes not possible to simulate a complex system in a single tool, but even if it is possible, very often, there are more suitable tools available for different subsystems. Ideally, every subsystem is modelled in a tool that meets the particular requirements for the domain and the structure of the model. (ii) The exchange of the black box models can be made without requiring their content to be disclosed, thereby protecting intellectual property and avoiding licensing fees. Therefore, co-simulation supports cross-company and cross-discipline developments. (iii) The robustness and computational performance are considered as the main weaknesses of state-of-the-art co-simulation tools and methods.

In the area of district-scale energy systems, there are highly specialized modelling and simulation tools, each of which is tailored to the needs of a specific engineering field and domain (e.g. IDA ICE and EnergyPlus for buildings or TRNSYS for HVAC system). Therefore, cosimulation is a promising approach to leverage existing tools for urban energy systems as well as engineering expertise that is often closely linked to specific tools.

\section{Paper Objective}

The contributions of this work are twofold: First, we present a workflow for automatic model generation of district energy systems. Second, we show the possibilities of a dynamic system simulation by linking the tools IDA ICE, Dymola and TRNSYS in a co-simulation framework. The paper will describe a case study (see Figure 1) of a virtual district including a discussion of different energy supply variants.

\section{Methods}

This paper provides a workflow for assessing energy supply strategies in district energy systems introducing three main improvements compared to the state-of-theart: (i) the data preparation is carried out using Vectorworks (2018) and QGIS (2018). This combines the benefits of QGIS in data collection, management and administration and Vectorworks in graphical representation; (ii) a novel pipe-laying algorithm with grid dimensioning is introduced, which allows the user to design new network topologies with reasonable pipe dimensions; (iii) a co-simulation framework is applied to assess energy supply variations. The workflow is divided into following process steps:

1. Pre-processing

2. Simulation of heating demand and load for buildings

3. Laying a heating network

4. Network dimensioning

5. Simulation of the heating network

6. Co-simulation framework

7. Evaluation of simulation result

\section{Pre-processing}

The first step in any case study is always pre-processing. This includes collecting the data, processing the data, filling in data gaps and storing the data. These steps are 
usually time-consuming and therefore robust and timesaving solutions with clear and illustrative presentations are required.

Geographical information systems (GIS) provide opportunities to collect, manipulate, visualize and analyse spatial input data. Thus, the actual state of study areas can be established quickly and the results can be displayed as different layers. Urban development areas are difficult to design in GIS software, however, because they are not based on 3D bodies. Planning tools for architects and urban developers use 3D-based software, which has the capability to generate illustrative designs for both interior and exterior spaces. Therefore, this study combines the benefits of Vectorworks and the open source tool QGIS. The building stock, which consists of the ground plan as 2D geometry and the mean building height and the building type as attributes, can be exported from QGIS to Vectorwoks via shape file. New buildings can be added in Vectorworks and exported back to QGIS, in which the Vectorlayers are linked to a PostgreSQL database (2018). The database stores all simulation-relevant data and their results (Nageler et al., 2017).

\section{Simulation of heating demand and load for buildings}

In this study, a building model generation tool (Nageler et al., 2018a) is used to reduce the enormous effort required for manual modelling. This tool generates dynamic physical building models, which is an interface between a PostgreSQL database and the dynamic building simulation tool IDA ICE. The tool extracts the required data from the database and creates an .idm file, which is the IDA ICE standard format. The building model is created within a four-step workflow. First, the building`s geometry is modelled, which consists of the ground plan and the mean building height. The building is represented by vertically layered thermal zones in dependence on the number of different uses. The building envelope is then modelled by using constructions including wall layers and materials. The next step is the modelling of the building usages and this is done by means of load profiles for occupancy, lightning and equipment from the SIA (2006). The last step is the modelling and parametrizing of the heating system. Predefined and scalable heating system types for district heating connection, ambient air or ground heat pumps, boilers or solar thermal plants are used for this purpose. Finally, the simulation results are stored in the database using scripts, which import the results from text files.

\section{Laying a heating network}

Heating networks have gained special significance in the period of energy transition. Here, the topology of heating networks has a significant impact on the overall system. On the one hand, plans from existing networks can be imported as layers added to the QGIS. On the other hand, a pipe-laying algorithm is needed that take into account the geographic and economic components for the optimal topology of new large-scale networks.

In this context, the paper therefore presents a pipe-laying algorithm that connects the energy supply unit and the customers with a heating network. These pipes are laid along the street network, which can be obtained from OpenStreetMap (2018). Roads are presented as lines with coordinates, which can be read by a script and stored in the database. Figure 1 shows the flow chart of the algorithm. The algorithm is explained on the basis of one energy supply unit, but can also be applied for several units. The algorithm is illustrated with sample images a-i) in Figure 1, the network extensions are displayed in violet, the already created network in red, the closest network connection point in pink, the buildings under consideration in pale green and the supply unit as a green point. All the buildings are first connected to the street network by adding the shortest connections between the centre of the buildings and the street network (see Figure 1a). Two possibilities are considered in the algorithm:

1. connect all buildings

2. connect selected buildings considering heat density

(1) All the buildings are connected to the network, taking into account the optimal geometry by expanding the network systematically. The shortest route from the energy supply unit to the customers is chosen as the starting connection (see Figure 1b). Following on from this all customers are connected to the heating network one after the other by adding the shortest route from the nearest customer to the network (see Figure 1c and d). Figure 1e shows the finished network topology, in which all customers are connected to the supplier.

(2) If the heat demand is taken into account, all the shortest connections of the buildings to the supply unit are stored in an auxiliary layer (see Figure 1f; each route is displayed as different colour). This makes it easier to compare routes, e.g., to quickly identify routes with adjoining sections. The heat density refers to the pipe sections in $\mathrm{kWh} / \mathrm{a} / \mathrm{m}$ pipe. The heat densities of the possible network extensions are then calculated, see Figure 1g, which shows 8 potential customers with their partially joining connections. If the minimum heat density in the pipe and the minimum heat demand of the customers are exceeded, then the customers that meet the criteria will be added to the network. The network continues to be extended in this manner until no further connections are found. Subsequently all the remaining customers (sorted by heat density) are checked to establish whether several customers collectively achieve the minimum heat density. For this, the minimum heat density in pipes with adjoining sections is checked by taking all the remaining consumers with adjoining connections into account one after the other until the criterion (minimum heat density) is met. The joining connections are identified by searching the auxiliary layer with the shortest connections. Figure $1 \mathrm{~h}$ shows such an example in which the existing network is extended with one customer with the highest heat density and four other customers to achieve the necessary minimum heat density through joining paths. The yellow line indicates the connection to the customer with the highest heat density and the joining connections with the other customers are depicted in green points. If a network connection with several customers has been found, the algorithm searches again for connections with individual customers. If no 


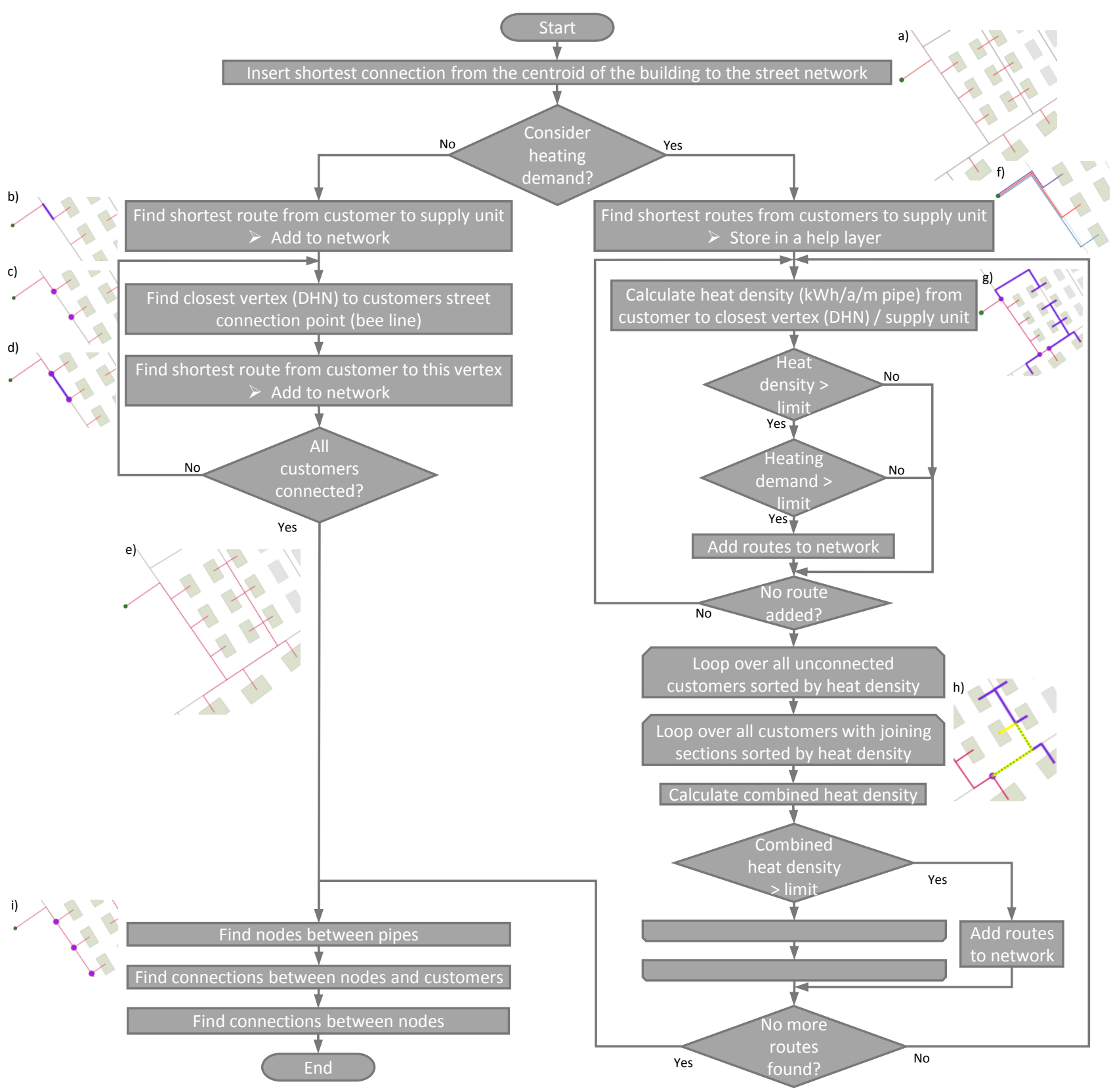

Figure 1: Flow chart of pipe laying algorithm.

more connections are found, all nodes are searched for between pipes (see Figure 1i). Furthermore, the pipe connections to the nodes and customers are clearly listed.

The algorithm was implemented using SQL functions, which are implemented in the packages PostGIS (2018) and pgRouting (2018) routines. The Dijkstra algorithm (Sedgewick, 1992) in the pgRouting package is used to calculate the shortest connection between two points.

\section{Network dimensioning}

Once the network topology has been established, the appropriate pipe diameter must be established in line with the economic considerations. In this study, each pipe is sized based on Frederiksen and Werner (2013). Their sizing process for a single pipe is transferred to a heating network with multiple pipes considering their coincidence factors for heat load diversity.
The design is based on the maximum mass flow rate, which was calculated in advance by means of the heating load simulation for the building. The network topology and the heat load determine the maximum mass flow in each pipe. The shortest path of the customer to the supply unit is used again to determine how the customers should obtain their heat. The mass flows are calculated by assuming a desired temperature difference between supply and return flow. The heating loads in the pipes are cumulated in adjoining sections. The diversity of the heating load is taken into consideration by using a coincidence factor, which approaches 0.45 as the number of customers increases. This effect smooths the load peaks. The pipe diameters are chosen in dependence on the flow velocity. The permissible flow rates increase with higher flow rates. The diameters and insulations were chosen according to the gradations of isoplus preinsulated steel pipes (2018). 


\section{Simulation of the heating network}

The framework in (Schweiger et al., 2017) is used to automatically generate a Modelica model (2018) of the heating network based on the resulting network topology. The Modelica model is created based on a unified network representation implemented in the Python package NetworkX (2018). The pipe model developed in (van der Heijde et al., 2017) is used to model the fluid transport in the network; the consumer model in (Schweiger et al., 2017) is adapted to enable the communication with Building Controls Virtual Test Bed (BCVTB) (2018). The data exchange between BCVTB and Dymola is handled with the socket in the Modelica Buildings library (Wetter et al., 2014).

\section{Co-simulation framework}

Co-simulation is a promising approach for the analysis of complex multi-domain systems that leverage mature simulation tools of the interfering domains. In this study, a co-simulation framework is thus used, which couples the simulation tools: Dymola (2018) for the heating network simulation, IDA ICE (EQUA, 2018) for the building and substation simulation and TRNSYS (2018) for the simulation of energy supply system. To this end, the co-simulation platform BCVTB is used that can connect a number of simulation tools according to the principle of loose coupling (Wetter, 2011), which means the required data is exchanged after each simulation timestep.

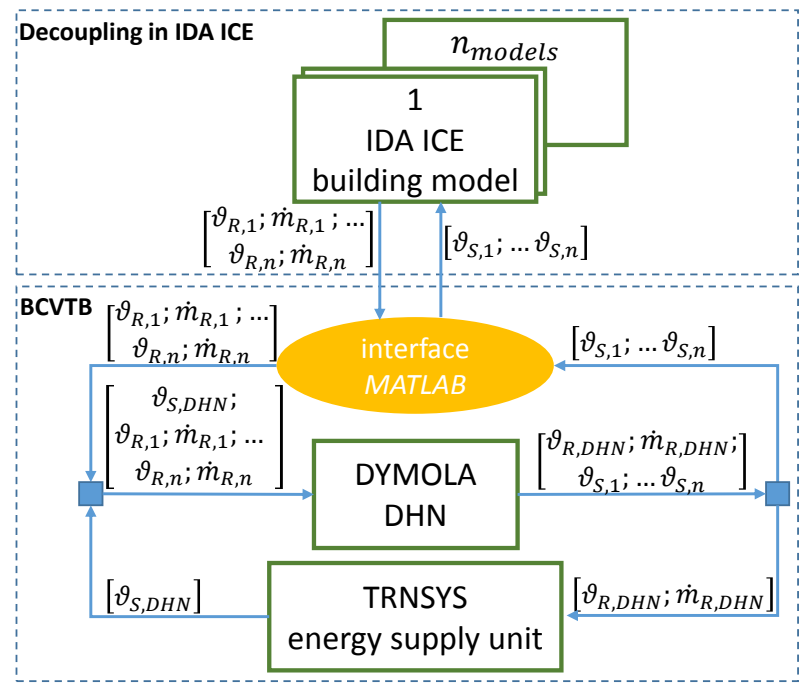

Figure 2: Co-simulation framework.

Figure 2 shows the co-simulation framework and the data exchange between these tools. In this study, an interface was used to link the BCVTB with IDA ICE (Nageler et al., 2018b). The data is thus exchanged via Matlab (MathWorks, 2018). In contrast to Matlab and BCVTB, IDA ICE uses a variable time step, which causes a small error due to data extrapolation. The magnitude of the error depends strongly on the maximum simulation time step in IDA ICE (Nageler et al., 2018b).

The exchanged data and their direction are shown in Figure 2 by arrows and variables in brackets. In this study, the substations of each building adjust the mass flow $\left(\dot{m}_{R, i}\right)$ of the heating network (Dymola), which is modelled in IDA ICE. The substation receives the supply temperature $\left(\vartheta_{S, i}\right)$ from the district heating network and calculates the mass flow and the return temperature $\left(\vartheta_{R}\right)$. Dymola calculates the supply temperature for each customer based on the supply temperature of the heating network $\left(\vartheta_{S, D H N}\right)$ and the mass flows in the substations in each of the buildings. The energy supply system receives the network return temperature $\left(\vartheta_{R, D H N}\right)$ and total mass flow of the heating network $\left(\dot{m}_{R, D H N}\right)$ from Dymola and heats the water to the required supply temperature. The exported values of each simulation tool are checked in BCVTB with a limiter, which restricts the mass flow and temperature values to a lower and upper limit.

\section{Evaluation of simulation results}

The building`s heating demand can be presented in a clear and brief manner by using geographical information systems. QGIS provides options to depict heat maps, 3D visualizations and animations. A heat map depicts hotspots with a high-energy and low energy consumption in colour codes. Energy suppliers can use heat maps to identify suitable districts for new heating networks or heating network extensions. The size and the form of a heat map strongly influences their appearance. For example, smoothed heat maps show a good overview of the study area (Nageler et al., 2018b).

Finally, the simulation results of the co-simulation framework must be evaluated. The setting of accurate dimensions and the controls for the heating system can be checked quickly by plotting the room air temperatures of each building. On the one hand, the presentation of the results of the energy supply system can be divided into the energy-technical operation of the system. These include temperature profiles, e.g., heat storages or geothermal fields, mass flows or energy balances. On the other hand, the implementation-relevant data such as costs and $\mathrm{CO}_{2}-$ equivalent emissions are relevant for investors. The operating costs can be evaluated from the heat quantity. The $\mathrm{CO}_{2}$-equivalent emissions are relevant for the approval procedures in the implementation due to environmental precautions.

\section{Case study}

The presented method has been tested on the basis of a virtual case study (see Figure 3), which was designed on the model of a European small town with a typical composition of buildings of different architectural epochs. The energy-technical modelling comprises a pie-shaped part of the city with 1549 buildings with a gross floor area of more than 2.8 million square meters. The building typological composition of a medieval core, closed and open perimeter block development, row buildings and individual buildings, as well as the usage structure and the age structure of the buildings corresponds to the type of a typical, historically grown, European small town (Albers, 1975).

A dairy is located in the periphery area with a waste heat potential of $4500 \mathrm{MWh} / \mathrm{a}$ and a maximum power of 1.5 MW. Two processes can be used in the dairy as waste heat with a temperature level of $80{ }^{\circ} \mathrm{C}(2900 \mathrm{MWh})$ and 
$60{ }^{\circ} \mathrm{C}$ (1600 MWh). The surrounding buildings, which meet the required conditions such as minimum heat consumption for economic operation or the consideration of other supply strategies, should be supplied with waste heat via a heat network from the dairy. The supply area should be chosen in such a way that the required annual energy demand may exceed the annual waste heat by about twice in order to keep the auxiliary heating low.

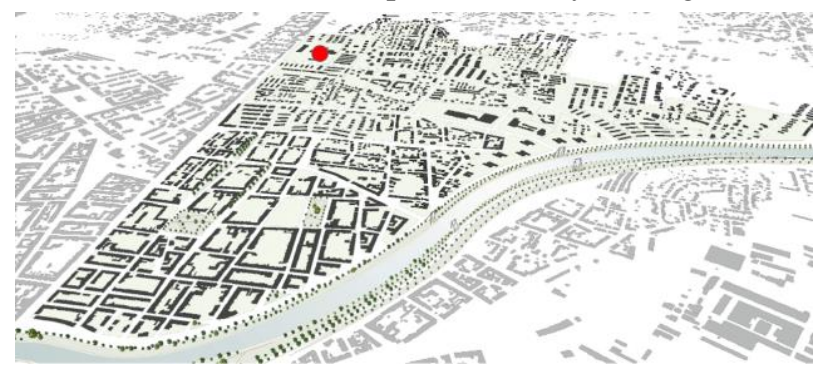

Figure 3: Case study with waste heat potential from a dairy (red point); modelled in Vectorworks.

The case study is divided into six parts including different energy supply variations. Table 1 provides an overview of the simulation scenarios. In variant 1 , the required heat quantity is provided by means of a thermal gas power plant. In variant 2 , the waste heat from the dairy is used. In this variant, however, the waste heat cannot be fully exploited due to the temporal discrepancy between waste heat potential and utilization. Therefore, in variant 3 , a pit thermal heat storage is loaded with the surplus heat during the summer and this reserve is discharged in the winter months. The pit thermal heat storage and the auxiliary heater are located directly adjacent to the dairy. In variants 4 to 6 , the energy supply system is identical, but a global warming future is taken into account with an estimated mean ambient temperature increase of $2{ }^{\circ} \mathrm{C}$ (UN Climate change conference Paris, 2015).

Table 1: Overview of the simulation scenarios.

\begin{tabular}{|c|c|c|c|c|}
\hline Variants & Waste heat & Heat storage & Climate 2018 & Climate $+2^{\circ} \mathrm{C}$ \\
\hline V1 & $\bar{x}$ & $\bar{x}$ & $\checkmark$ & $\bar{x}$ \\
\hline V2 & $\checkmark$ & $x$ & $\checkmark$ & $x$ \\
\hline V3 & $\checkmark$ & $\checkmark$ & $\checkmark$ & $x$ \\
\hline V4 & $x$ & $x$ & $x$ & $\checkmark$ \\
\hline V5 & $\checkmark$ & $x$ & $x$ & $\checkmark$ \\
\hline V6 & $\checkmark$ & $\checkmark$ & $x$ & $\checkmark$ \\
\hline
\end{tabular}

The co-simulation approach is suitable for this case study as different domains are considered: heat supply, heat distribution and heat consumption in buildings. TRNSYS provides sophisticated solutions to model the energy supply system including the models for a pit thermal heat storage, a gas auxiliary heater (modelled as ideal heater) and waste heat utilization and models for their control strategy. Dymola offers promising models for thermal network simulation (Schweiger et al., 2018a) and IDA ICE provides scalable solutions for dynamic building simulation (Sahlin, P. and Lebedev, A., 2016). In the studied variants, co-simulation is not necessary between the heat distribution system and the energy supplier, since there is no reciprocal interaction between heat supplier and heat consumer, because the demand of the customers is covered at all times. A simulation of the energy supply system would thus also be possible via load file. However, in the constellation with co-simulation, additional variants with supply bottlenecks can be evaluated. The cosimulation between the heat delivery system and the utility is mandatory, as a changed flow temperature requires a different mass flow and vice versa.

Figure 4 shows a simplified representation of the energy supply unit in TRNSYS Studio for the versions 3 and 6 with the pit thermal heat storage (Type342). The energy supply unit controls the network supply temperature (Tvl_Calc) as a function of the ambient air temperature (sliding average over one day; Type 84 ). The $80{ }^{\circ} \mathrm{C}$ waste heat (WasteHeat_Calc; red connection lines) is used directly via a bypass (Type11f) if needed and the surplus is used to charge the heat storage. In order to use the $60{ }^{\circ} \mathrm{C}$ waste heat (orange line), the heat storage is loaded if the temperature in the storage center is less than $75^{\circ} \mathrm{C}$, otherwise the $60{ }^{\circ} \mathrm{C}$ temperature level would recool the heat storage. The stored heat is discharged (Type11h) if either too little or no waste heat can be used directly. If the temperature of the waste heat and the storage tank are above the required supply temperature, the supply flow is recooled by means of an admixing circuit (Type $11 \mathrm{~b}$ and Type11h-3). A lack of heat reaching the required temperature is dealt with through the application of a gas auxiliary heater (Type6). The data exchange for cosimulation is implemented via Type6666.

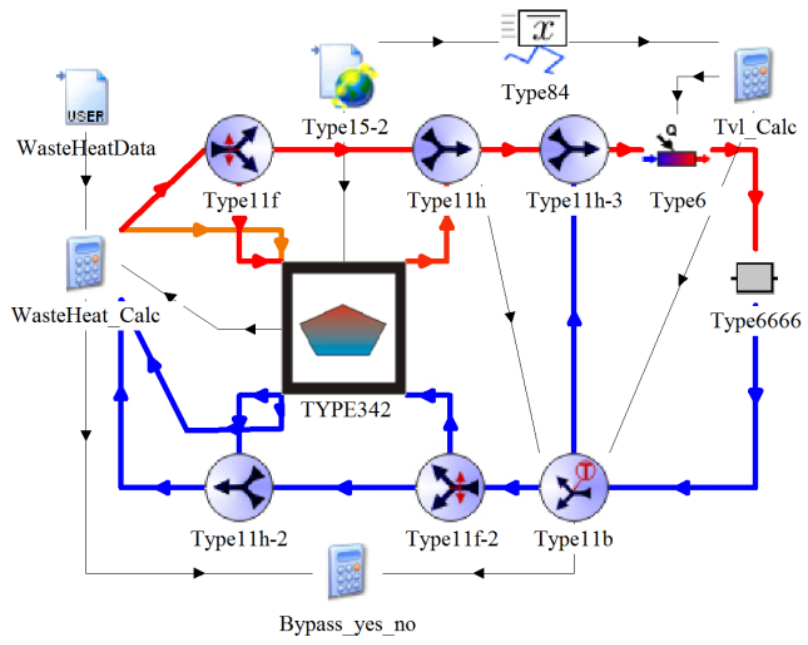

Figure 4: Energy supply unit in TRNSYS.

\section{Results and Discussion}

This chapter presents the results and a discussion of the introduced workflow, which is applied to the virtual case study. First, the heating demand for the building is presented. Next, the network topology is shown on the basis of the pipe laying algorithm and subsequent adaptions. Finally, the temporal courses and energy balances of the energy supply system are presented.

The heating demand of the buildings is shown in Figure 5 in form of a smoothed heat map in a 10×10 m grid. The colour gradient of the heat map ranges from green $\left(0-5 \mathrm{kWh} / \mathrm{m}^{2} / \mathrm{a}\right)$ to pink $\left(80-120 \mathrm{kWh} / \mathrm{m}^{2} / \mathrm{a}\right)$. The buildings, which are included in this calculation, are indicated bordered in grey. Derived from the energy consumption, the heating network was created with the pipe making algorithm (see Figure 5; black lines). The 
potential customers are shown in Figure 5 in pale green. Other customers are excluded because of the availability of other energy supply concepts such as gas networks. The boundary conditions for network generation were that the energy density in the pipe exceeds $500 \mathrm{kWh}$ per meter of pipe and year and that the annual energy consumption of a building exceeds $10 \mathrm{MWh}$. Subsequently, additional customers were connected to the heating network (see Figure 5; blue lines). This can be understood, e.g. as a local energy supply policy. In total, 149 customers were connected to the network with a pipe length of $12 \mathrm{~km}$.

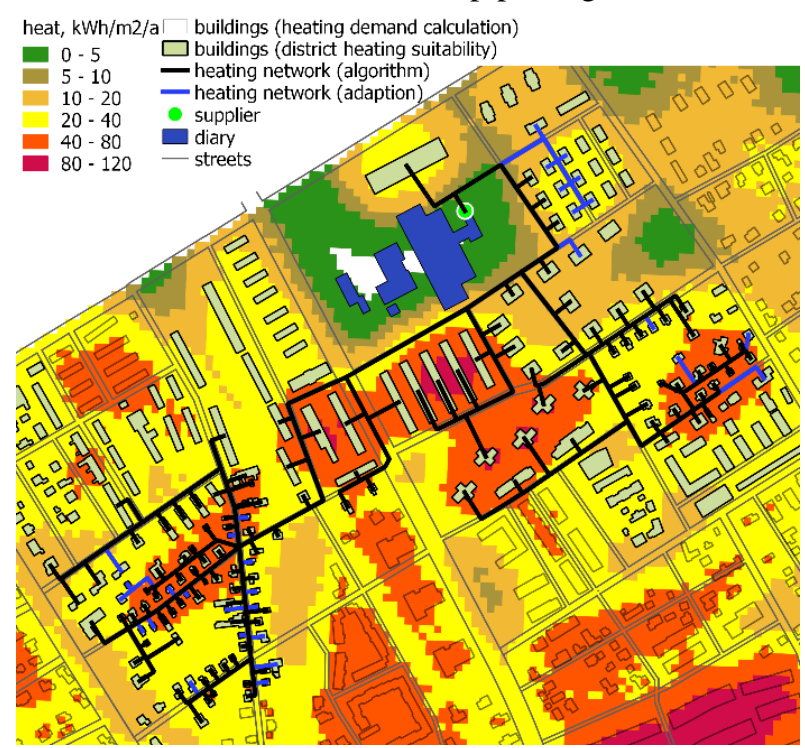

Figure 6 shows a comparison of the daily average heating load as a function of the climate. The daily average outdoor temperature is shown in the subplot a) of Figure 6 with a mean temperature increase of $2{ }^{\circ} \mathrm{C}$ in the future climate. The annual solar radiation remains almost the same. Figure 6b) shows the heating provision of the energy supply system, which is composed of the energy demand of the connected buildings and the heat losses of the heating network. Furthermore, the figure shows that the waste heat potential exceeds the demand in the summer. As a result, it is not possible to use the entire waste heat potential directly in summer. A pit thermal heat storage is thus implemented in the simulation variants 3 and 6. The size of the storage has been varied until the waste heat loads the middle layer of the storage to temperatures above $75^{\circ} \mathrm{C}$. Consequently, a $20000 \mathrm{m3}$ storage was chosen, which has a height of $12 \mathrm{~m}$ and a mean insulation thickness of $0.5 \mathrm{~m}$. Figure 7 shows the temperature layering in pit thermal heat storage at top, middle and bottom. Due to the shorter heating period in variant 6 resulting from the warmer climate, the heat storage charges earlier and stays warm longer in autumn. After switching off the $60^{\circ} \mathrm{C}$ waste heat (above $75^{\circ} \mathrm{C}$ in the middle of the storage tank), the storage temperatures in the middle rises to $77.5{ }^{\circ} \mathrm{C}$ in $\mathrm{V} 3$ and $76.0^{\circ} \mathrm{C}$ in $\mathrm{V6}$, but the temperature drops in the layers at the bottom of the storage facility.

Figure 5: Heating network topology of the case study.

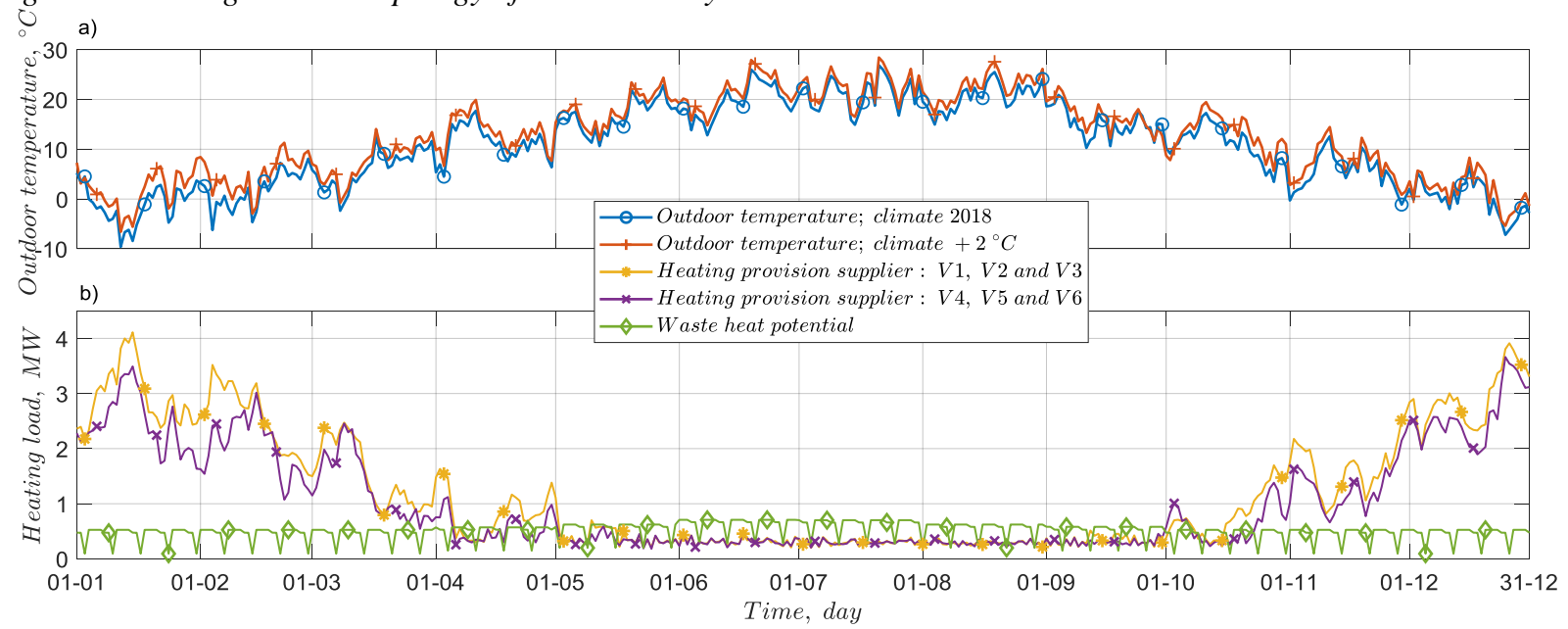

Figure 6: Daily average values of a) outdoor temperature and b) the heating load with waste heat potential.

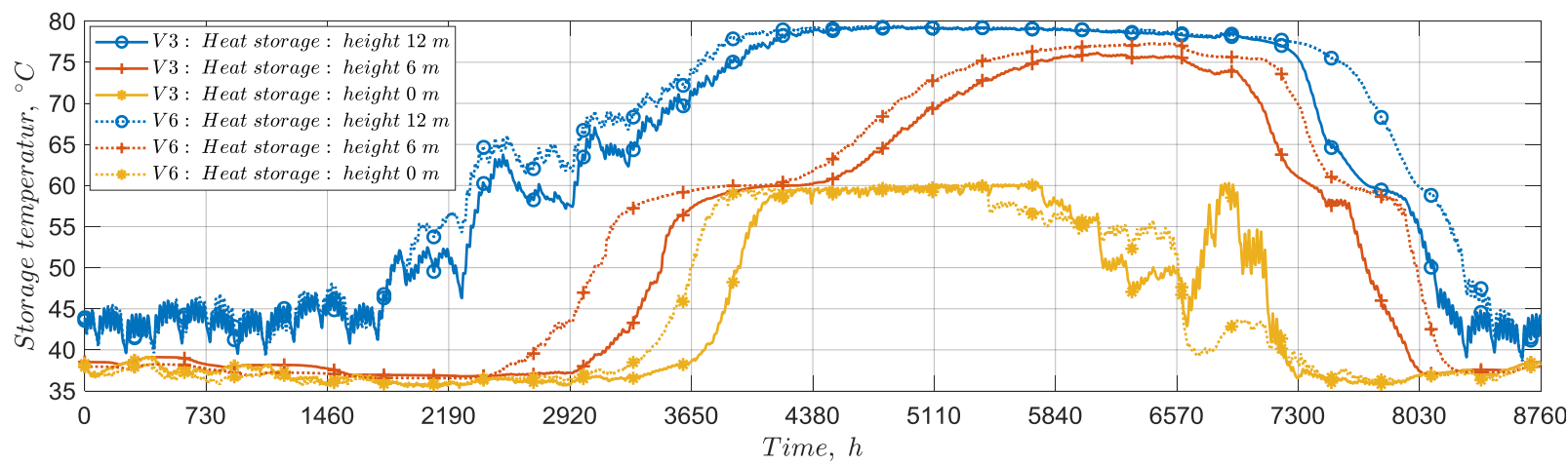

Figure 7: Temperature layering in the pit thermal energy storage (V3 \& V6): top (12m), middle (6m) and bottom (Om). 
Figure 8 shows the monthly energy balance of the pit thermal heat storage for the simulation variants 3 (subplot a) and 6 (subplot b). The energy balance is composed of the $60{ }^{\circ} \mathrm{C}$ and $80^{\circ} \mathrm{C}$ waste heat that loads the storage, the heat release from the storage, the heat losses and the change of internal energy. In the winter months from November to February, the $80^{\circ} \mathrm{C}$ waste heat is used almost entirely directly (thus no energy is delivered to the storage facility) and the storage is thus charged with $80^{\circ} \mathrm{C}$ waste heat only from March. The $60^{\circ} \mathrm{C}$ waste heat has no bypass, so the total energy produced is loaded to the storage facility. In contrast to the $80{ }^{\circ} \mathrm{C}$ waste heat, the $60{ }^{\circ} \mathrm{C}$ waste heat cannot be fully utilized in the summer months, because the storage tank has already reached a higher temperature level. This temperature level is also apparent in the storage losses, which increase in the summer visibly from $11 \mathrm{MWh} /$ month in January to $22 \mathrm{MWh} / \mathrm{month}$ in July. The change in internal energy is equivalent to the loading and unloading of the heat storage, which shows that the storage is charged from March to August. The comparison between the two variants with different climates clearly shows that in V6 even in December a significant part of the heat can be removed from the heat storage.

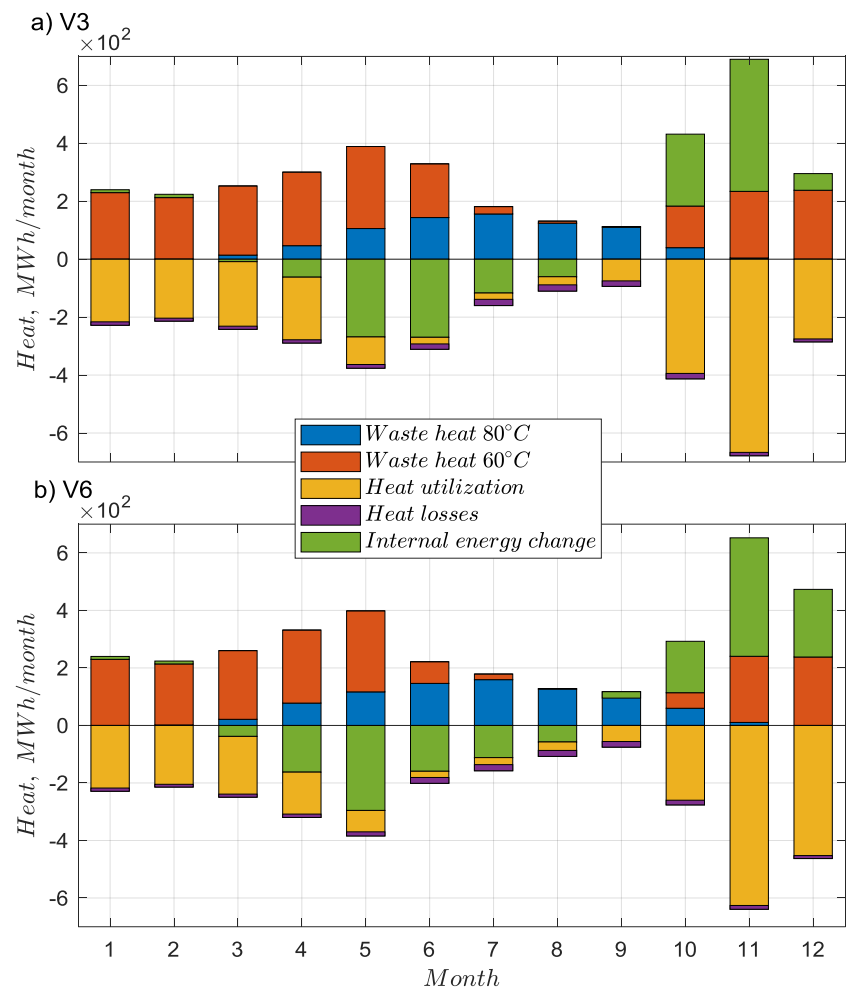

Figure 8: Monthly energy balance of the pit thermal heat storage.

Figure 9 shows the annual energy balance and the $\mathrm{CO}_{2}$ equivalent emissions of the simulation variants. Subplot a) shows how the heat demand of the customers is covered and how much of the available waste heat can be used. Due to the use of waste heat, $4150 \mathrm{MWh} / \mathrm{a}$ in V2 and $3950 \mathrm{MWh} / \mathrm{a}$ in V5 can be saved from the gas auxiliary heater. However, some of this waste heat remains unused (18\% V2 and $20 \% \mathrm{~V} 5$ ) because the heat supply does not always match the heat demand. The gas reheating can be further reduced by means of the heat storage, which saves $850 \mathrm{MWh} / \mathrm{a}$ in V3 and V6. However, the annual heat losses of the storage tank are $178 \mathrm{MWh}$ in $\mathrm{V} 3$ and $180 \mathrm{MWh}$ in V6.

Subplot b) in Figure 9 shows the biggest contributors to $\mathrm{CO}_{2}$ equivalent emissions. The electricity demand of the buildings, the pumping power of the heating network, the waste heat and the heat supply from the gas auxiliary heater are integrated in the comparison. The electricity demand of the buildings was calculated by means of internal load profiles for light and equipment, which amounts in total to $2500 \mathrm{MWh} / \mathrm{a}$. The pumping current which is necessary for the operation of the heat network was calculated via the pressure loss in the network and is $12 \mathrm{MWh} / \mathrm{a}$. The different sources of energy are evaluated by means of conversion factors. Conversion factors were chosen in accordance with OIB Guideline 6 (2015) with conversion factors of $236 \mathrm{~g} \mathrm{CO}_{2} / \mathrm{kWh}$ for gas, $20 \mathrm{~g} \mathrm{CO}_{2} / \mathrm{kWh}$ for waste heat and $276 \mathrm{~g} \mathrm{CO}_{2} / \mathrm{kWh}$ for electricity. The future energy transition has been integrated with own assumptions, reducing the conversion factors for electricity to 69 (75\% reduction) and gas to $189 \mathrm{~g} \mathrm{CO}_{2} / \mathrm{kWh}$ (20\% reduction). The figure shows that $\mathrm{CO}_{2}$ emissions can be reduced from 3230 to $1880 \mathrm{~g} \mathrm{CO}_{2}$ solely by altering the climate and increasing the use of renewable energy sources. Furthermore a saving of $27 \%$ in V2 and $35 \%$ is achieved in V5 through the use of waste heat. The installation of a pit storage lowers emissions by another $8 \%$ in V3 and $13 \%$ in V6 (compared to V2/V5).

\section{Conclusion}

This paper presents a workflow for dynamic simulation of large-scale district energy systems with the introduction of three main improvements compared to the state of the art: i) The data preparation is carried out using Vectorworks and QGIS; ii) A novel pipe-laying algorithm with pipe dimensioning is introduced; iii) A co-simulation framework is applied to assess energy supply variations.

The method was applied to a virtual case study, which consists of 149 buildings connected to an energy supply system with a heating network. Different supply strategies are compared by means of temporal courses, heat and $\mathrm{CO}_{2}$ balances. Furthermore, the impact of global warming on the energy supply is investigated. Based on this case study, the following conclusions can be drawn:

- The dynamic interactions between buildings, heating networks and energy supply systems can be modelled by means of the proposed workflow.

- Seasonally fluctuating waste heat can be utilized using pit thermal energy storage facilities.

- Climate change scenarios must be considered to avoid oversizing the energy supply system.

- Waste heat utilization reduces the primary energy demand and the $\mathrm{CO}_{2}$ equivalent emissions. 


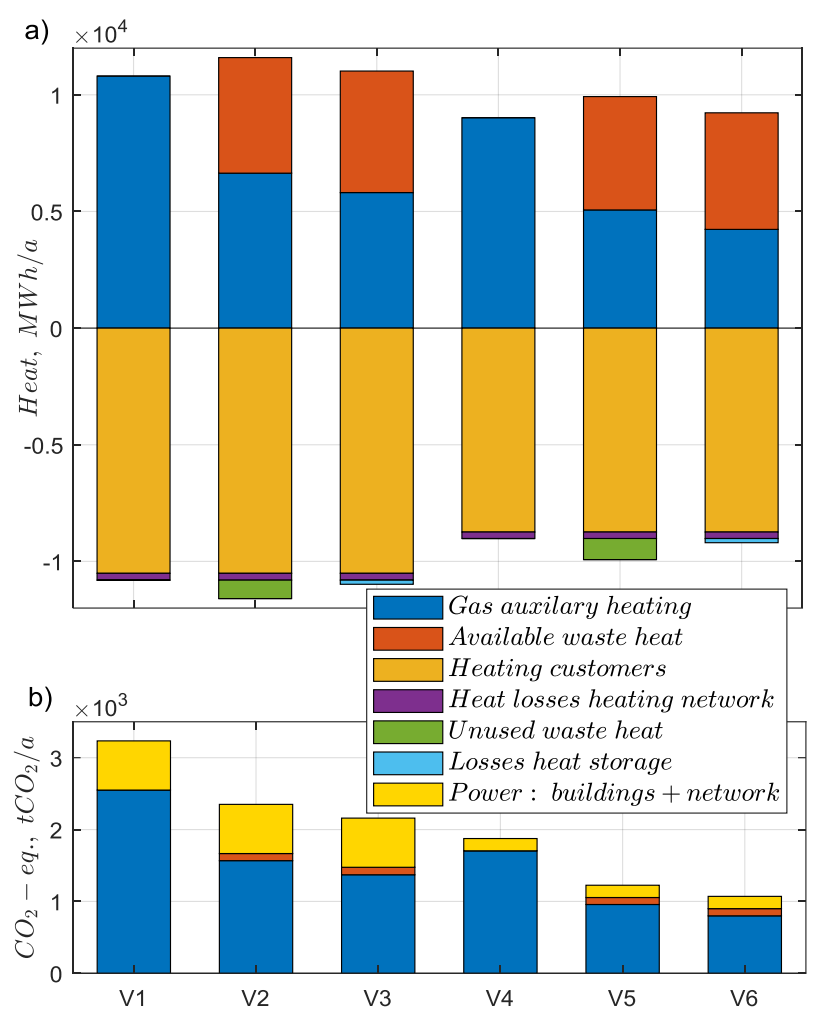

Figure 9: Annual energy balance of the simulation variants.

\section{Acknowledgement}

The reported research was supported by the Austrian Federal Ministry of Transport, Innovation and Technology (bmvit) and is associated with the project "DeStoSimKaFe - Konzeptentwicklung \& gekoppelte deterministisch/stochastische Bewertung Kalter Fernwärme zur Wärme- \& Kälteversorgung" (Project No. 865010).

\section{References}

Albers, G. (1975). Entwicklungslinien im Städtebau. Bertelsmann Fachverlag. Düsseldorf (D).

Building Controls Virtual Test Bed (BCVTB) (2018). http://simulationresearch.lbl.gov/bcvtb

Dymola (2018). https://www.3ds.com/productsservices/catia/products/dymola/

EQUA (2018). http://www.equa.se/en/

Frederiksen, S., Werner, S. (2013). District Heating and Cooling. Studentlitteratur AB. Lund (SE).

Isoplus (2018). http://www.isoplus-pipes.com/home.html

MathWorks (2018). https://de.mathworks.com/products/matlab.html

Modelica (2018). https://www.modelica.org/

Nageler, P., Zahrer, G., Heimrath, R., Mach, T., Mauthner, F., Leusbrock, I., Schranzhofer, H., Hochenauer, C. (2017) Novel validated method for GIS based automated dynamic urban building energy simulations. Energy 139, 142-154.
Nageler. P., Mach. T., Heimrath, R., Schranzhofer, H., Hochenauer, C. (2018a) Generation tool for automated thermal city modelling. Appl Mech Mater 887, 292-299.

Nageler, P., Schweiger, G., Schranzhofer, H., Mach, T., Heimrath, R., Hochenauer, C. (2018b) Novel method to simulate large-scale thermal city models. Energy 157, 633-646.

NetworkX (2018). https://networkx.github.io/

OIB (2015). RL-6: Energy behavior of buildings. Austrian Institute of Construction Technology, Vienna Austria.

OpenStreetMap (2018). https://www.openstreetmap.org pgRouting (2018). https://pgrouting.org/

PostGIS (2018). https://postgis.net/

PostgreSQL (2018). https://www.postgresql.org

QGIS (2018). https://www.qgis.org/en/site/

Sahlin, P., Lebedev, A. (2016). OPENCPS: benchmark building and energy system models.

Schweiger, G., Heimrath, R., Falay, B., O’Donovan, K., Nageler, et al. (2018a). District energy systems: Modelling paradigms and general-purpose tools. Energy 164, 1326-1340.

Schweiger, G., Gomec, C., Engel, G., Hafner, I., Schöggl, J., Posch, A., \& Nouidui, T. S. (2018b). An Empirical Survey on Co-simulation: Promising Standards, Challenges and Research Needs. Under Review.

Schweiger, G., Larsson, P., Magnusson, F., Lauenburg, P., \& Velut, S. (2017). District heating and cooling systems - Framework for Modelica-based simulation and dynamic optimization. Energy 137, 566-578.

Sedgewick, R. (1992). Algorithms in C++. AddisonWesley. Bonn (DEU).

SIA (2006). Standard-Nutzungsbedingungen für die Energie- und Gebäudetechnik, Swiss Society of Engineers and Architects, SIA 2024.

TRNSYS (2018). http://www.trnsys.com/

UN climate change conference Paris (2015). http://www.un.org/sustainabledevelopment/cop21/

van der Heijde, B., Fuchs, M., Ribas Tugores, C., et al. (2017). Dynamic equation-based thermo-hydraulic pipe model for district heating and cooling systems. Energy Conversion and Management 151, 158-169.

Vectorworks (2018). https://www.vectorworks.net/en

Wetter, M. (2011). Co-simulation of building energy and control systems with the building controls virtual test bed. J Build Perform Simul 4(3),185-203.

Wetter, M., Zuo, W., Nouidui, T. S., \& Pang, X. (2014). Modelica Buildings library. J Build Perform Simul 7(4), 253-270. 